\title{
Influence of glycosides on behavior of Oenococcus oeni in wine conditions: growth, substrates and aroma compounds
}

\author{
Carmen Maturano $^{1} \cdot$ Fabiana María Saguir $^{2}$
}

Received: 4 February 2017 / Accepted: 19 June 2017

(C) Springer Science+Business Media B.V. 2017

\begin{abstract}
Autochthonous Oenococcus oeni strains (MS9, MS20 and MS46) with good malolactic performance and yielding adequate diacetyl levels, were selected to investigate the effect of synthetic and grape glycosides on bacterial growth, substrate utilization and $\beta$-glucosidase $(\beta \mathrm{Glu})$, $\alpha$-arabinofuranosidase ( $\alpha$ Ara) and $\alpha$-rhamnopyranosidase $(\alpha$ Rha) activities in a wine-like medium containing 6\% ethanol, $\mathrm{pH} 4.0$ (WBM). Then, changes in the volatile compounds profile were evaluated at the end of malolactic fermentation (MLF) carried out by the MS46 strain in WBM containing $1 \mathrm{mg} \mathrm{L}^{-1}$ of natural glycoside. All strains grew and efficiently degraded L-malic acid in WBM where $\beta$ Glu and $\alpha$ Ara activities were found but not $\alpha$ Rha. In presence of a synthetic glycoside (eriodictyol 7-O- $\beta$-rutinoside) $\beta \mathrm{Glu}$ activity was significantly enhanced for two of the cultures tested (MS20 and MS460) while a low $\alpha$ Rha activity was induced, presenting MS46 the better performance. Glycosides extracted from fermented grape musts under different conditions allowed maximum growths, L-malic acid utilization rates and glycosidase activities in the MS46 strain. Thus, $\beta$ Glu, $\alpha$ Ara and $\alpha$ Rha activities increased between $30-50$ and $3-11 \%$ respectively. This indirectly correlated to significant changes in total esters and higher alcohols at the end of MLF, which increased by up to 140 and $30 \%$ respectively. Moreover, ethyl and acetate esters formed up
\end{abstract}

Fabiana María Saguir

fabianasaguir@fbqf.unt.edu.ar

1 Instituto de Investigación y Desarrollo en Ingeniera de Procesos, Biotecnología y Energías Alternativas (PROBIEN, CONICET), Facultad de Ingeniería, Universidad Nacional del Comahue, Buenos Aires 1400, 8300 Neuquén, Argentina

2 Instituto de Microbiología, Facultad de Bioquímica, Química y Farmacia, Universidad Nacional de Tucumán, Ayacucho 491, 4000 Tucumán, Argentina to 100-fold than alcohols or esters degraded highlighted the main role of this microorganism in the esters synthesis. Results obtained encourage the potential use of selected indigenous $O$. oeni strains as a tool to enhance wine complexity through MLF, mainly on highly fruity aroma.

Keywords Oenococcus oeni $\cdot$ Metabolism $\cdot$ Glycosides · Aroma $\cdot$ Wine

\section{Introduction}

In chemistry, a glycoside is a molecule in which a sugar is bound to another functional group (phenol, aliphatic alcohol, flavonoid, saponin, anthraquinone, thiol compound, etc.) via a glycosidic bound. These compounds which constitute a reserve of powerful odor active-compounds are largely present in grapes as $\beta$-D-glucosides, often structured as simple $\beta$-D-glucopyranoside in which the volatile aglycon is bound to a glucose moiety through $\beta$-glycosidic linkage (Ugliano et al. 2003) or, as disacarides in which the glucose moiety is further substituted with a second sugar such as $\alpha$-L-arabinopyranose, $\alpha$-L-rhamnopyranose, $\beta$-Dapiofuranose and $\beta$-D-xylopyranose (Gûnata et al. 1988). Analyses carried out by direct determination of glycosides have shown that most glycosides in grapes are diglycosides (Voirin et al. 1992), being the aglycone moiety often dominated by monoterpenes, $\mathrm{C}_{13}$-norisoprenoids and benzene derivatives (Orrillo et al. 2007).

Many white wines and almost all red wines undergo secondary or malolactic fermentation (MLF), in which L-malic acid is decarboxylated into L-lactic acid. This bioconversion is carried out by lactic acid bacteria (LAB), being Oenococcus oeni the specie better adapted to the low $\mathrm{pH}$ values and high ethanol and sulfur dioxide concentrations 
of wine (Maturano et al. 2016; Tristezza et al. 2016). Microbiological stability and flavor modification of wine are also outcomes of MLF with a broad range of secondary compositional changes that include amino acids and polyols metabolism, esters synthesis and glycosides hydrolysis (Bartowsky et al. 2002; Liu 2002). Of the many fermentation-derived volatile compounds that contribute to wine aroma and flavor, the esters are of major importance for fruity sensory properties and overall quality of wine (Costello et al. 2013). Therefore, specific O. oeni strains well-adapted to perform MLF might represent a source of enzymes capable of operating under the physicochemical conditions of wine, thereby influencing on its flavor (Barbagallo et al. 2004). Saguir et al. (2009) demonstrated that the majority of the $O$. oeni strains isolated from Argentinean wines at the beginning of MLF showed detectable $\beta$-glucosidase activity in whole cells. In concordance to these findings, Grimaldi et al. (2000) demonstrated a significant $\beta$-glucosidase activity in several $O$. oeni strains whereas Boido et al. (2002) reported a decrease of glycosylated aroma compounds during MLF of Tannat wines. However, Mansfield et al. (2002) reported the production of $\beta$-glycosidase enzyme in $O$. oeni strains, although their culture failed to hydrolyze native grape glycosides. In addition, several studies have focused on the influence of $\mathrm{pH}$, temperature, sugar and ethanol content on $\beta$-D-glucosidase activities of $O$. oeni (Boido et al. 2002; D'Incecco et al. 2004; Grimaldi et al. 2005a, b; Bloem et al. 2008; Gagné et al. 2011; Maturano et al. 2016). However, data are still scarce and often contradictory. Besides, little is known about the influence of synthetic and natural glycosides on different glycosidase activities as well as other parameters including growth, substrates degradation and volatile compounds profile (D'Incecco et al. 2004; Gagné et al. 2011).

Nowadays, the use of $O$. oeni strains as malolactic starter cultures to improve process efficiency and wine quality is a desirable winemaking practice. However, MLF induction by use of commercially available strains is not always successful, because wine is a very harsh environment for bacterial growth (low $\mathrm{pH}$, low nutrients availability and ethanol and sulphur dioxide presence) (Saguir and Manca de Nadra 2002; Spano and Massa 2006; Lombardi et al. 2012). In addition, the use of MLF starter cultures of LAB strains selected from the indigenous wine microbiota of each region takes advantage of the natural adaptation of the strains to the wine characteristics, and may simultaneously preserve the characteristics of regional wines (Izquierdo et al. 2004). Thus, three $O$. oeni strains were selected from a wide group of strains because they all showed good malolactic potential and from a physiological point of view they produced adequate diacetyl levels and $\beta$-D-glucosidase activities under some conditions relevant for winemaking (Saguir et al. 2009; Maturano et al.
2016). So, the objective of the present study was to investigate the behavior of the selected $O$. oeni strains in terms of growth, L-malic acid degradation and $\beta$-glucopyranosidase, $\alpha$-arabinofuranosidase and $\alpha$-rhamnopyranosidase activities in a wine-like medium with or without supplementation with synthetic and grape glycosides. In the strain that showed the best behavior, changes in the volatile compounds profile after MLF were also determined. Results obtained will allow gaining information more precise of aroma production by $O$. oeni strains that enable oenologists and researchers the criteria to select a specific bacterium.

\section{Materials and methods}

\section{Microorganism}

Oenococcus oeni MS9, MS20 and MS46 isolated from wines (Malbec variety) from a cellar from Cafayate, Salta, Argentina were selected by exhibiting $\beta$-glucosidase activity in whole cells and adequate diacetyl production under different growth conditions (Saguir et al. 2009; Maturano et al. 2016).

The microorganisms were maintained at $-20^{\circ} \mathrm{C}$ in De Man Ragosa-Sharpe's medium (MRS) (De Man et al. 1960) (Oxoid Ltd., London, England) supplemented with $15 \%(\mathrm{v} / \mathrm{v})$ tomato juice (MRST) and glycerol $(30 \%, \mathrm{v} / \mathrm{v})$.

\section{Media, growth conditions and culture procedures}

A wine-like semi-synthetic medium (Reguant et al. 2000) was used as basal medium (WBM) with the following composition (in $1 \mathrm{~L}$ ): Glucose, $1.0 \mathrm{~g}$; fructose, $1.0 \mathrm{~g}$; trehalose, $1.0 \mathrm{~g}$; tartaric acid, $1.0 \mathrm{~g}$; L-malic acid, $2.0 \mathrm{~g}$; citric acid, $1.0 \mathrm{~g}$; sodium acetate, $0.14 \mathrm{~g}$; yeast extract (Difco, Detroit, MI, USA), $4.0 \mathrm{~g}$; casamino acids (Difco Detroit, MI, USA), $2.5 \mathrm{~g} ; \mathrm{KH}_{2} \mathrm{PO}_{4}, 0.3 \mathrm{~g} ; \mathrm{KCl}, 0.22 \mathrm{~g}$; L-cysteine- $\mathrm{HCl} 0.5 \mathrm{~g}$; $\mathrm{MgSO}_{4} \cdot 7 \mathrm{H}_{2} \mathrm{O}, 0.065 \mathrm{~g} ; \mathrm{MnSO}_{4} \cdot \mathrm{H}_{2} \mathrm{O}, 0.015 \mathrm{~g} ; \mathrm{CaCl}_{2}$, $0.065 \mathrm{~g}$; glycerol $2.9 \mathrm{~mL}(\mathrm{v} / \mathrm{v})$.

The $\mathrm{pH}$ was adjusted to $\mathrm{pH} 4.0$ with $10 \mathrm{mM} \mathrm{NaOH}$ before sterilization $\left(121^{\circ} \mathrm{C}, 15 \mathrm{~min}\right)$. Cysteine- $\mathrm{HCl}$ was sterilized by filtration through a $0.22 \mu \mathrm{m}$ pore size membrane (Millipore) and then added to the sterile medium. WBM was supplemented with $1 \mathrm{mg} \mathrm{mL}{ }^{-1}$ of synthetic glycoside, eriocitrin (eriodictyol 7-O- $\beta$-rutinoside, $\mathrm{C}_{27} \mathrm{H}_{30} \mathrm{O}_{15}$, Sigma-Aldrich, inc. FLUKA) (WBME) or with 1 and $5 \mathrm{mg} \mathrm{mL} \mathrm{mL}^{-1}$ of glycosides extracted from Malbec grape must with (fractioned heating and subsequent inoculation) or without treatment before extraction. Synthetic and natural glycosides were sterilized by filtration through a nylon membrane $(0.22 \mu \mathrm{m}$ pore size, Millipore $)$ and added to sterile WBM. All media were adjusted to a final ethanol 
content of $6 \%(\mathrm{v} / \mathrm{v})$ according to results described for $O$. oeni by Reguant et al. (2000).

For inoculation, cells were grown in MRST pH 4.8 without agitation at $30^{\circ} \mathrm{C}$, harvested at the end of exponential phase $(80 \mathrm{~h})$ and pre-cultured in a nutritionally depleted medium (MRS with $4 \mathrm{~g} \mathrm{~L}^{-1}$ of yeast extract, $2 \mathrm{~g} \mathrm{~L}^{-1}$ of $\mathrm{L}$-malic acid and $1 \mathrm{~g} \mathrm{~L}^{-1}$ of fructose without peptone and meat extract, $\mathrm{pH} 4.0$ ), for cells adaptation before inoculation into the test media. After the third transfer, cells were harvested by centrifugation at the end of the exponential phase $(\sim 144 \mathrm{~h})$, washed twice with sterile distilled water to avoid the carry-over of nutrients and resuspended in the same diluent to optical density $\left(\mathrm{OD}_{560 \mathrm{~nm}}\right)$ : 1.0. Cell suspensions were used to inoculate individually the experimental media at a rate of $2 \%(\mathrm{v} / \mathrm{v})$. All cultures were carried out in triplicate and incubated at $25^{\circ} \mathrm{C}$ for 10 days. Samples were taken at regular time intervals for enzymatic determinations and supernatants were stored frozen $\left(-18^{\circ} \mathrm{C}\right)$ for subsequent chemical analysis.

\section{Bacterial count}

Bacterial growth was monitored by periodic $\mathrm{OD}_{560 \mathrm{~nm}}$ measurements using a spectrophotometer (WPA Bioware DNA, Biochrom, England). Cell cultures were diluted, if necessary, with sterile medium prior to measuring $\mathrm{OD}_{560 \mathrm{~nm}}$ to maintain linearity between OD and biomass. At the same time, the colony forming units were determined (cfu $\mathrm{mL}^{-1}$ ) by plating $0.1 \mathrm{~mL}$ of adequate dilution of inoculated media on MRST medium. Incubation time was 10 days at $30^{\circ} \mathrm{C}$.

\section{Glycosidase activities}

Enzymatic assays were performed as described by Maturano et al. (2016) using $p$-nitrophenyl- $\beta$-D-glucopyranoside (Sigma N7006), $\quad p$-nitrophenyl- $\alpha$-L-arabinofuranoside (Sigma N3641) and $p$-nitrophenyl- $\alpha$-L-rhamnopyranoside (Sigma N7763) as substrates for $\beta$-glucopyranosidase, $\alpha$-arabinofuranosidase and $\alpha$-rhamnopyranosidase enzymes, respectively. The enzyme assays were conducted in permeabilized cells according to a procedure optimized in our laboratory (Maturano et al. 2016). The enzymatic activity was expressed as unit (U) which was equivalent to $\mu \mathrm{mol}$ of $p$-nitrophenyl released per minute and $\mathrm{mL}$.

\section{Isolation and quantification of grape must glycosides}

\section{Grape must}

Grapes from Malbec variety picked at commercial maturity were used in this study, because it represents one of the most important red grapes varieties in Argentina. Grapes were collected directly from a vineyard (Cafayate, Salta) immediately before harvesting in plastic sterile bags and stored at $4{ }^{\circ} \mathrm{C}$ prior to use. Grapes were pressed and the must was divided into two fractions: untreated one (M, control), and the other treated by heating at $70^{\circ} \mathrm{C}$ for $20 \mathrm{~min}$ and cooled down to room temperature. This procedure was repeated for three consecutive days to eliminate natural microbiota (TM). The effectiveness of this treatment was verified by plate counting. Characteristics of the grape must used in this study were $24{ }^{\circ}$ Brix, total acidity $5.5 \mathrm{~g} \mathrm{~L}^{-1}$ and $\mathrm{pH}$ 3.6. $\mathrm{M}$ and $\mathrm{TM}$ samples were fermented by natural yeast microbiota and after inoculation with $2 \%(\mathrm{v} / \mathrm{v})$ pure Saccharomyces cerevisiae mc2 culture (Mendoza et al. 2007) respectively. Both alcoholic fermentations (spontaneous and controlled) were carried at $25 \pm 2{ }^{\circ} \mathrm{C}$ until reaching $4.5 \%$ alcohol and $16{ }^{\circ}$ Brix respectively (McMahon et al. 1999). Then, samples were centrifuged at $5000 \mathrm{rpm}$ for $10 \mathrm{~min}$ to remove natural or inoculated microbiota and the supernatants were filtered at $0.45 \mu \mathrm{m}$ pore membrane and preserved at $4{ }^{\circ} \mathrm{C}$.

\section{Extraction of glycosides}

Extraction was carried out according to protocol described by McMahon et al. (1999) by means of Waters $\mathrm{C}_{18}$ reverse phase Sep-Pak columns (Mildford, MA, USA) that were activated by passing through $10 \mathrm{~mL}$ methanol followed by $10 \mathrm{~mL}$ of deionized water. After loading $10 \mathrm{~mL}$ of undiluted sample (filtered supernatant) at room temperature, the columns were washed three times with $15 \mathrm{~mL}$ of deionized water and glycosides were eluted with $5 \mathrm{~mL}$ methanol. The glycosides eluted from columns were filtered and stored at $-20^{\circ} \mathrm{C}$ until required. Glycoside concentration extracted was estimated by the analysis of glycosyl-glucose (Williams et al. 1995) after acid hydrolysis.

\section{Glycoside acid hydrolysis}

Aliquots $(0.5 \mathrm{~mL})$ of eluted samples were added to $\mathrm{H}_{2} \mathrm{SO}_{4}$ $(1.0 \mathrm{~mL}, 2.25 \mathrm{M})$ to give solution that contained $1.5 \mathrm{M}$ $\mathrm{H}_{2} \mathrm{SO}_{4}$ and $10 \%$ (v/v) ethanol. A negative control prepared with water $(1.0 \mathrm{~mL})$ was added instead of $\mathrm{H}_{2} \mathrm{SO}_{4}$ solution for free glucose determination (non-glycosidic fraction) of each eluate. At the same time, a reagent blank was made with ethanol $(0.5 \mathrm{~mL})$ to replace the glycoside eluted. The test samples and reagent blank placed in screw-capped test tubes were heated at $100 \pm 2{ }^{\circ} \mathrm{C}$ for $1 \mathrm{~h}$ while the negative control was held at room temperature. Then D-glucose was measured using an enzymatic method (Boehringer Kit, Germany). The difference between glucose obtained from acid hydrolysis and the negative control corresponding to glycosyl-glucose fraction was proportional to the amount of glycoconjugate precursors present in the eluate. Results 
indicated that the method employed extracted the glycosidic fraction at a concentration of $50 \mathrm{mg} \mathrm{L}^{-1}$.

\section{Analysis of aromatic profile}

Volatile aroma compounds were determined in free cell supernatants, which were thawed at room temperature before analysis and centrifuged at $2000 \times g$ during $5 \mathrm{~min}$. Aroma compounds were micro-extracted by headspacesolid-phase microextraction (HS-SPME) according to conditions described by Maturano et al. (2015). After pre-conditioning of the sample, SPME fibers $(2 \mathrm{~cm})$ were exposed to the headspace for $15 \mathrm{~min}$ at controlled temperature $\left(40^{\circ} \mathrm{C}\right)$ during the extraction process, and the fibers were inserted immediately into the $\mathrm{GC}$ injector port $\left(230^{\circ} \mathrm{C}\right)$ for 20 min for thermal desorption of the volatile compounds (Massera et al. 2012) which were then identified on a Varian CP-3800 gas chromatograph equipped with a splitless injector and a Saturn 2200 Ion Trap Mass Spectrometric detector (Varian, CA, USA). The system was operated with Saturn GC-MS Workstation software Version 6.41. The GC was equipped with a Factor Four VF5 column (30 $\mathrm{m} \times 0.25 \mathrm{~mm} ; 0.25 \mu \mathrm{m}$ film thickness, Varian, CA, USA). The column temperature was programmed at an initial value of $40^{\circ} \mathrm{C}(5 \mathrm{~min})$, followed by a gradual increase until $100^{\circ} \mathrm{C}$ at a rate of $1.5^{\circ} \mathrm{C} \mathrm{min}{ }^{-1}$. Then, the temperature was raised to $215^{\circ} \mathrm{C}(5 \mathrm{~min})$ at a rate of $3^{\circ} \mathrm{C} \mathrm{min}^{-1}$. Helium was used as carrier gas at a constant flow rate of $1.0 \mathrm{~mL} \mathrm{~min}^{-1}$. The injection port temperature was $230^{\circ} \mathrm{C}$. An electron impact (EI) of $70 \mathrm{eV}$ was used for ionization, and the temperature of the transfer line and the ion trap was $200^{\circ} \mathrm{C}$. Identification of volatile compounds was carried out by comparing them with the retention times and with

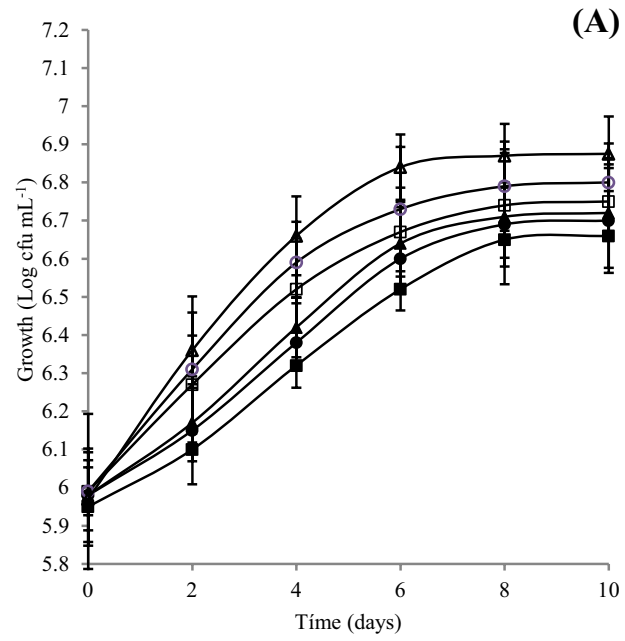

Fig. 1 Growth (A) and L-malic acid consumption (B) by $O$. oeni MS9 (open square, filled square), MS20 (open circle, filled circle) and MS46 (open triangle, filled triangle) in a wine-like medium the mass spectra from the Nist 2.0 library. They were quantified using relative areas related to the internal standard (Massera et al. 2012).

\section{Analytical methods}

D-Glucose and L-malic acid were measured by enzymatic methods (Boehringer Kits, Mannheim, Germany).

\section{Statistical analyses}

Experimental data were analyzed by one-way ANOVA and significant differences between mean values were determined by Tukey's test $(p<0.05)$ using InfoStat statistical software (2002).

\section{Results}

\section{Effect of eriocitrin on growth and glycosidase activities}

Growth parameters and L-malic acid consumption by the MS9, MS20 and MS46 strains were evaluated in a winelike medium with and without supplementation with the synthetic glycoside eriocitrin (WBME and WBM, respectively) (Fig. 1). As the bacteria cultures had been preadapted in a nutritionally deficient MRS medium, there was no initial lag period or decline in bacterial numbers in test culture media. In WBM, all the strains tested grew by $0.70 / 0.75 \log \mathrm{cfu} \mathrm{mL}^{-1}$ (measured as difference between stationary phase and inocula) with maximum growth rates $\left(\mu_{\max }\right)$ of $\sim 0.10 \mathrm{~h}^{-1}$, this kinetic parameter was determined in a 6 days' interval (exponential growth

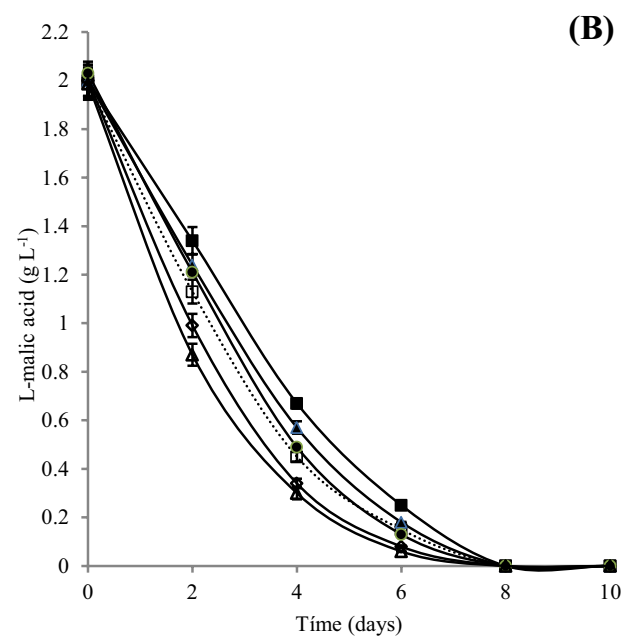

(WBM) (open symbols) and WBM supplemented with the synthetic glycoside eriocitrin at $1 \mathrm{mg} \mathrm{L}^{-1}$ (closed symbols). Values are the mean of triplicate determinations 
phase). The presence of eriocitrin enhanced these growth parameters from 7.0 to 22.3 and 19.3 to $31.8 \%$ respectively, showing the MS46 strain, in general, the best response (Fig. 1a). In both media, the utilization of L-malic acid by all strains tested began immediately as growth began and proceeded to complete depletion within 8 days incubation. Moreover, all they degraded up to $60 \%$ of initial L-malic acid within 4 days, even though its degradation rates per day increased of about $20 \%$ in the presence of synthetic glycoside respect to WBM (Fig. 1b). In these conditions, $\beta$-glucopyranosidase ( $\beta$ Glu), $\alpha$-arabinofuranosidase ( $\alpha$ Ara) and $\alpha$-rhamnopyranosidase ( $\alpha$ Rha) activities were measured against $p$-nitrophenyl-glycosides $(p \mathrm{NP})$ in permeabilized cells during bacterial growth (Table 1). Results showed detectable levels of $\beta$ Glu and $\alpha$ Ara activities at 2 days with maximum values at 6-8 days which ranged from 13 to $30 \mathrm{U}$ depending on enzyme, strain and/or eriocitrin presence. For example, maximum $\beta$ Glu activity of strain MS46 was enhanced by up to $10 \mathrm{U}$ in WBME compared to that obtained in WBM by day 8. In addition, it was $29.7 \%$ higher than that obtained for strain MS20. Total adding of the $\beta$ Glu activities of each strain across all times assayed in WBM or WBME confirmed the general trend of synthetic glycoside in increasing significantly the hydrolysis of $p \mathrm{NP}-\beta \mathrm{glu}$ with $O$. oeni MS46 showing the greatest overall value (Table 1). As mentioned above, all strains tested also possessed activity against $p \mathrm{NP}-\alpha$ Ara during bacterial growth. However, it did not result statically different regardless strain and eriocitrin presence for a given incubation time, reaching peaks by approximately $20 \mathrm{U}$ by day 6 . In contrast, $\alpha$ Rha activity of all tested strains was only detected in WBME and resulted significantly lower as those found for $\beta$ Glu and $\alpha$ Ara activities. Across three strains studied, once again MS46 possessed the greatest overall $\alpha$ Rha activity. Even though some absolute values could significantly differ, the studied strains revealed similar patterns in term of growth, malolactic and enzymatic activities in the wine-like medium and supplemented with eriocitrin. Hence, $O$. oeni MS46 was selected as representative for the next assays.

\section{Influence of grapes glycosides on growth and glycosidase activities}

Table 2 illustrates the growth kinetic of $O$. oeni MS46 and the consumption of L-malic acid in WBM supplemented with glycosidic extracts from fermented M and TM (NFG and CFG respectively), at 1 and $5 \mathrm{mg} \mathrm{L}^{-1}$. Similar values of $\mu_{\max }$ and final biomass (measured during exponential growth and as difference between stationary phase and inocula respectively) were found for all conditions studied with average values of $0.016 \mathrm{~h}^{-1}$ and $1.10 \log \mathrm{cfu} \mathrm{mL}^{-1}$, which were significantly higher as those obtained in WBM (between 40 and 63\% respectively) and WBME (between 15 and $25 \%$ respectively). Furthermore, L-malic acid was totally decarboxylated in shorter times. Thus, the mean consumption rate per day of L-malic acid was of about $0.44 \mathrm{~g} \mathrm{~L}^{-1}$ in the natural glycosides presence for both initial concentrations against $0.25 \mathrm{~g} \mathrm{~L}^{-1}$ in the presence of eriocitrin. The influence of the natural glycosides was also determined on glucose depletion pattern as shown in Fig. 2 for 1 or $5 \mathrm{mg} \mathrm{L}^{-1}$ of NFG. In both conditions glucose was not fully consumed at the end exponential bacterial growth; moreover, after this time (6 day) it increased of
Table 1 Glycosidic activities of $O$. oeni strains during growth in a wine-like medium (WBM) and supplemented with the synthetic glucoside eriocitrin (WBME)

\begin{tabular}{|c|c|c|c|c|c|c|c|c|c|c|}
\hline \multirow[t]{3}{*}{ Day } & \multirow[t]{3}{*}{ Medium } & \multicolumn{9}{|c|}{ Enzymatic activity (U) of $O$. oeni strains $^{\mathrm{a}}$} \\
\hline & & \multicolumn{3}{|c|}{$\beta$-Glucosidase } & \multicolumn{3}{|c|}{$\alpha$-Arabinosidase } & \multicolumn{3}{|c|}{$\alpha$-Rhamnosidase } \\
\hline & & MS9 & MS20 & MS46 & MS9 & MS20 & MS46 & MS9 & MS20 & MS46 \\
\hline \multirow[t]{2}{*}{2} & WBM & $4.1^{\mathrm{aX}}$ & $5.0^{\mathrm{aX}}$ & $5.2^{\mathrm{aX}}$ & $5.9^{\mathrm{aX}}$ & $4.7^{\mathrm{aX}}$ & $5.5^{\mathrm{aX}}$ & ND & ND & ND \\
\hline & WBME & $4.2^{\mathrm{aX}}$ & $5.3^{\mathrm{aX}}$ & $6.4^{\mathrm{aX}}$ & $6.9^{\mathrm{aX}}$ & $5.5^{\mathrm{aX}}$ & $5.9^{\mathrm{aX}}$ & $1.5^{\mathrm{aX}}$ & $0.6^{\mathrm{aY}}$ & $0.9^{\mathrm{aY}}$ \\
\hline \multirow[t]{2}{*}{4} & WBM & $12.2^{\mathrm{bX}}$ & $11.7^{\mathrm{bX}}$ & $12.9^{\mathrm{bX}}$ & $12.0^{\mathrm{bX}}$ & $11.2^{\mathrm{bX}}$ & $12.2^{\mathrm{bX}}$ & ND & ND & ND \\
\hline & WBME & $12.7^{\mathrm{bX}}$ & $17.6^{\mathrm{cdX}}$ & $17.0^{\mathrm{bcX}}$ & $13.7^{\mathrm{bcX}}$ & $12.1^{\mathrm{bX}}$ & $13.6^{\mathrm{bX}}$ & $2.1^{\mathrm{abY}}$ & $0.9^{\mathrm{aX}}$ & $2.6^{\mathrm{bY}}$ \\
\hline \multirow[t]{2}{*}{6} & WBM & $17.0^{\mathrm{bcX}}$ & $13.2^{\mathrm{bcX}}$ & $15.6^{\mathrm{bcX}}$ & $18.7^{\mathrm{cX}}$ & $18.2^{\mathrm{cX}}$ & $19.8^{\mathrm{cX}}$ & ND & ND & ND \\
\hline & WBME & $21.2^{\mathrm{cX}}$ & $18.0^{\operatorname{cdX}}$ & $24.3^{\mathrm{deX}}$ & $21.1^{\mathrm{cX}}$ & $21.7^{\mathrm{cX}}$ & $23.3^{\mathrm{cX}}$ & $3.3^{\mathrm{bXY}}$ & $1.9^{\mathrm{bX}}$ & $3.6^{\mathrm{cY}}$ \\
\hline \multirow[t]{2}{*}{8} & WBM & $16.9^{\mathrm{bcX}}$ & $13.3^{\mathrm{bcX}}$ & $19.0^{\mathrm{cdX}}$ & $18.3^{\mathrm{bcX}}$ & $16.4^{\mathrm{cX}}$ & $18.3^{\mathrm{cX}}$ & ND & ND & ND \\
\hline & WBME & $21.6^{\mathrm{cXY}}$ & $21.1^{\mathrm{dX}}$ & $30.0^{\mathrm{eY}}$ & $20.7^{\mathrm{bX}}$ & $20.6^{\mathrm{cX}}$ & $21.6^{\mathrm{cX}}$ & $3.4^{\mathrm{bX}}$ & $2.0^{\mathrm{bX}}$ & $3.4^{\mathrm{cX}}$ \\
\hline Total & WBM & $50.2^{\mathrm{eX}}$ & $43.3^{\mathrm{eX}}$ & $52.7^{\mathrm{eX}}$ & $55.0^{\mathrm{eX}}$ & $50.5^{\mathrm{eX}}$ & $60.0^{\mathrm{eX}}$ & ND & ND & ND \\
\hline
\end{tabular}

"Like wine" WBM was supplemented with $1 \mathrm{mg} \mathrm{L}^{-1}$ of eriocitrin

Different letters within row ( $\mathrm{a}, \mathrm{b}, \mathrm{c}, \mathrm{d}, \mathrm{f}, \mathrm{e})$ and the same files $(\mathrm{X}, \mathrm{Y}, \mathrm{Z})$ indicate significance with a $p$ value $<0.05$ for a given activity. Means with the same letter are not significantly different. Values are the means of three independent experiments

$N D$ not detected

${ }^{a}$ Determinations were carried out in permeabilized cells obtained at different times of incubation (day) 
Table 2 Influence of natural glycosides extracted from fermented grape must (untreated or treated) on growth and L-malic acid degradation in O. oeni MS46

\begin{tabular}{|c|c|c|c|c|}
\hline \multirow[t]{2}{*}{ Parameter } & \multicolumn{4}{|c|}{ WBM added with glycosides extracted from grape must ${ }^{\mathrm{a}}$} \\
\hline & NFG1 & NFG5 & CFG1 & CFG5 \\
\hline $\mathrm{A}^{*}$ & $1.00 \pm 0.02(40.7,15.0)$ & $1.06 \pm 0.02(46.8,20.0)$ & $1.10 \pm 0.02(57.7,24.1)$ & $1.11 \pm 0.03(53.1,25.2)$ \\
\hline$\mu_{\max }\left(\mathrm{h}^{-1}\right)$ & $0.016 \pm 1 \times 10^{-4}(52.3,15.3)$ & $0.016 \pm 2 \times 10^{-4}(55.4,17.9)$ & $0.016 \pm 2 \times 10^{-4}(58.5,20.2)$ & $0.017 \pm 1 \times 10^{-3}(63.1,23.8)$ \\
\hline L-Malic acid $\left(\mathrm{g} \mathrm{L}^{-1}\right)^{\mathrm{b}}$ & ND (4) & $\mathrm{ND}(4)$ & $0.06 \pm 2 \times 10^{-3}(4)$ & $\mathrm{ND}(4)$ \\
\hline
\end{tabular}

(.) Represents stimulation percentages of parameters A and $\mu_{\max }$ related to values obtained in WBM, WBM supplemented with eriotricin (WBME) or day at which the acid was totally consumed

Values are the means of duplicate determinations in three independent experiments

$N D$ not detected

*Difference in cell concentration $\left(\log \mathrm{cfu} \mathrm{L}^{-1}\right)$ between stationary phase and inocula

${ }^{a}$ Wine-like basal medium (WBM) was supplemented with 1 or $5 \mathrm{mg} \mathrm{L}^{-1}$ of glycosides extracted from must fermented by natural microbiota and treated by heating and fermented with a yeast pure culture (NFG1 or NFG5 and CFG1 or CFG5 respectively)

${ }^{\mathrm{b}}$ Initial L-malic acid concentration, $2.0 \pm 0.1 \mathrm{~g} \mathrm{~L}^{-1}$

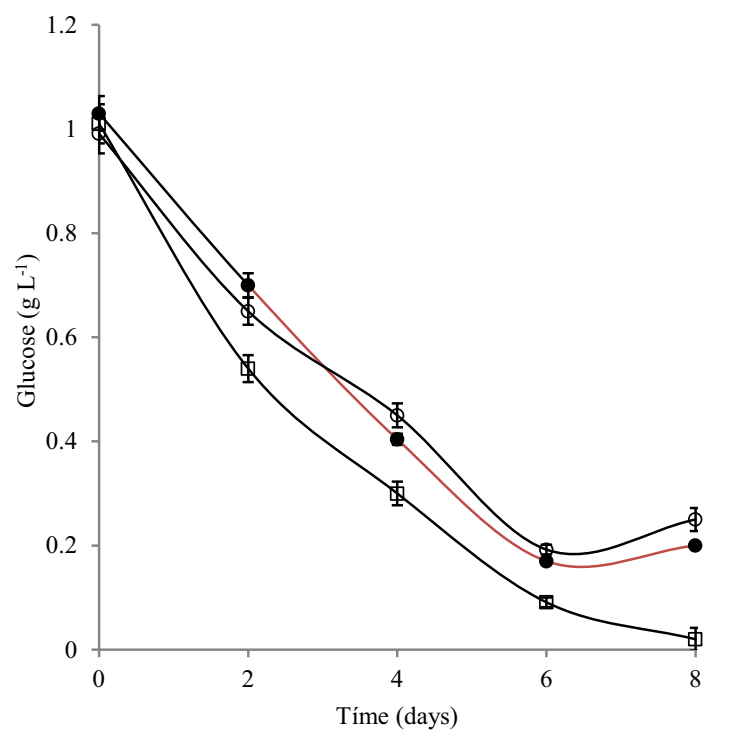

Fig. 2 Changes in residual glucose during growth of $O$. oeni MS46 in a wine-like medium (WBM) (open square) and added with the natural glycoside NFG at $1 \mathrm{mg} \mathrm{L}^{-1}$ (filled circle) and $5 \mathrm{mg} \mathrm{L}^{-1}$ (open circle). Values are the mean of triplicate determinations

about $30 \%$. Over the courses of glucose and L-malic acid degradation, the $\beta \mathrm{Glu}, \alpha \mathrm{Ara}$ and $\alpha \mathrm{Rh}$ a activities of $O$. oeni MS46 were measured in WBM added with 1 and $5 \mathrm{mg} \mathrm{L}^{-1}$ of NFG (Fig. 3). Results demonstrated that they increased by $\sim 35 \%$, between $30-50$ and $3-11 \%$ compared to those obtained in WBME regardless concentration of glycoside assayed, respectively. Moreover, $\beta$ Glu activity increased in $40 \%$ at second day of culture in the NFG presence respect to WBME, while for the other two enzymes maximum increases were seen at 6 days incubation. Similar results were obtained when WBM was supplemented with CFG for both concentrations tested.
As similar behavior was found for the MS46 strain in the presence of the natural glycosides regardless type of AF carried out before extraction and concentration tested, a representative condition was selected for studying the changes in aroma profile following MLF by $O$. oeni MS46.

\section{Profile of volatile compounds in WBM supplemented with grape glycoside}

Table 3 shows the changes in the volatile compounds profile determined by HS-SPME/GC-MS after FML (8 days) carried out by $O$. oeni MS46 in WBM plus $1 \mathrm{mg} \mathrm{L}^{-1} \mathrm{NFG}$. At the same time, uninoculated medium was evaluated. A total of 44 compounds were identified before MLF including esters, terpenoids and alcohols in total concentrations of $320.89,276.15$ and $169.04 \mu \mathrm{g} \mathrm{L}^{-1}$, respectively and, in minor proportion $\mathrm{C}_{13}$ norisoprenoides and other compounds like aldehydes. Isobornyl acetate and 4-tert-butylcyclohexyl acetate, dihidromircenol and cis-mirtanol and, 2-butyloctanol and 1-hexadecanol were the most abundant volatile compounds in the initial pools of esters, terpenoids and alcohols respectively.

After MLF, the total content of esters and aliphatic alcohols increased by up to 140 and $30 \%$ respectively, while the group of "other compounds" decreased $50.6 \%$ relative to its initial concentration. The significant increase of esters correlated well with the formation of new acetate and ethyl fatty acids ones such as 3-methylbutyl acetate (197.29 $\left.\mu \mathrm{g} \mathrm{L}^{-1}\right)$, ethyl octanoate $\left(153.22 \mu \mathrm{g} \mathrm{L}^{-1}\right)$, ethyl hexanoate $\left(98.56 \mu \mathrm{g} \mathrm{L}^{-1}\right)$, 4-tert-butylcyclohexyl acetate (63.20 $\mu \mathrm{g} \mathrm{L}^{-1}$ ) and the increment of isobornyl acetate (41\%) rather than with the loss of some of them which accounted for $22.7 \%$ of its initial concentration. FML also had effect on the formation of new alcohols such as 2-phenyl ethanol $\left(1.95 \mu \mathrm{g} \mathrm{L}^{-1}\right)$ and 2-methyl hexadecanol 
Fig. 3 Glycosidic activities observed during growth of O. oeni MS46 in presence of natural glycoside NFG at 1 (filled bar) and $5 \mathrm{mg} \mathrm{L}^{-1}$ (open bar) against $p$-nitro-phenyl $\beta$-Dglucopyranoside (A), $p$-nitrophenyl $\alpha$-D-arabinofuranoside (B), and $p$-nitro-phenyl $\alpha$-D-rhamnopyranoside (C). Values are relative (\%) to the activity observed for the control performed under the same condition in presence of synthetic glycoside (WBME) instead of natural one. Values are the mean of triplicate determinations. Different letters show significant differences $(p \leq 0.05)$ between different concentrations of glycoside and incubation times for each enzyme
(A)
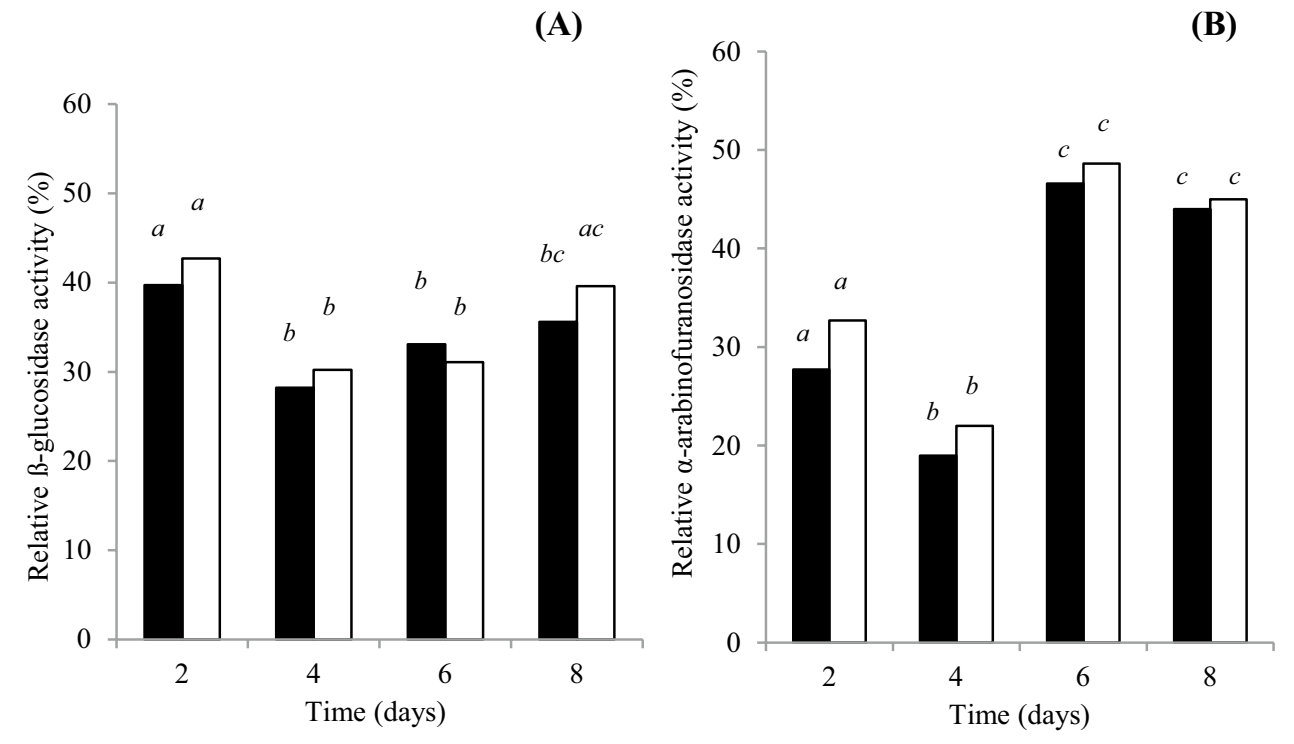

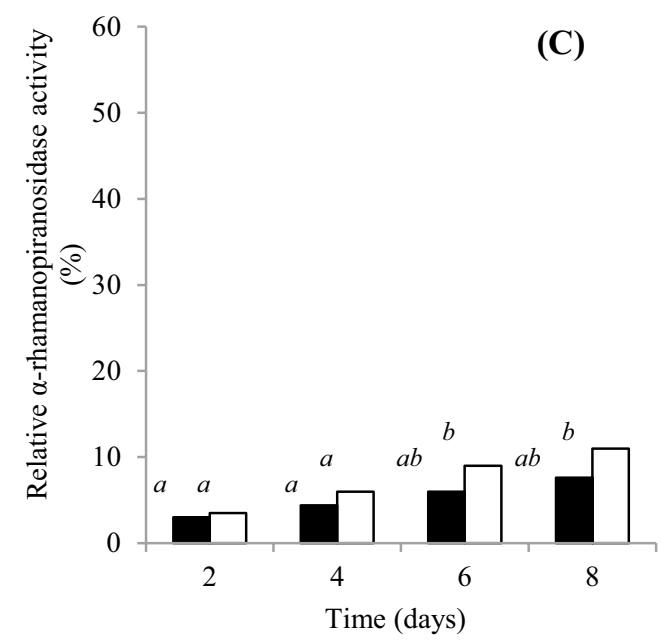

(1.44 $\mu \mathrm{g} \mathrm{L}^{-1}$ ) while 4-tert-butylcyclohexanol and menthol increased $\sim 30 \%$. However, the total amount of esters formed was up to 100-times higher than for alcohols formed or esters consumed. Terpenoids and $\mathrm{C}_{13}$-norisoprenoides were scarcely affected after MLF, however, small increases of $\beta$-citronellol and 1,2-epoxy limonene were detected while others decreased. In addition, the aldehydes 3-methylbutanal, 2-methylbutanal and $\alpha$-hexylcinnamaldehyde decreased while 2-butyltetrahydrofuran was newly formed. In the uninoculated medium, the composition of volatile compounds remained almost unchanged, confirming that all changes were produced by the growth and metabolism of the MS46 strain.

\section{Discussion}

Research in progress is showing that LAB can modify some of the components and sensory properties of wine.

In this context glycosidases activities are of interest as they are involved in the release of volatile aroma compounds (Hernandez-Orte et al. 2009; Segurel et al. 2009; Mtshali et al. 2012; Campbell-Sills et al. 2016). However, their activity during wine fermentation has mostly concerned to $\beta$ Glu from O. oeni (Grimaldi et al. 2000; Mansfield et al. 2002; Mtshali et al. 2012). In this work, we investigated the behavior in terms of growing, substrates degradation and glycosidase activities of $O$. oeni strains in a wine-like medium (WBM) supplemented with synthetic and natural glycosides in order to enable a better understanding of the importance of this species to aroma formation through MLF. The tested strains were selected on previous screenings yielding diacetyl levels below the taste threshold and detectable $\beta$ Glu cell surface activities in MRS medium under different experimental conditions (Saguir et al. 2009; Maturano et al. 2016).

In this present study, all strains tested grew in WBM, $\mathrm{pH} 4.0$, although at a lower extent and, efficiently degraded 
Table 3 Volatile compounds in a wine-like medium supplemented with glycoside extracted from fermented grape must $\left(1 \mathrm{mg} \mathrm{L}^{-1}\right)$ at the end of MLF carried out by O. oeni MS46

\begin{tabular}{|c|c|c|}
\hline Compounds $\left(\mu \mathrm{g} \mathrm{L}^{-1}\right)$ & Control & O. oеni MS46 \\
\hline \multicolumn{3}{|l|}{ Esters } \\
\hline Hexyl acetate & ND & $2.68 \pm 0.89$ \\
\hline 2-Methylpropyl acetate & $21.16 \pm 0.61$ & ND \\
\hline 3-Methylbutyl acetate & ND & $197.29 \pm 8.15$ \\
\hline 4-Tert-butylcyclohexyl acetate & $69.58 \pm 2.28$ & $63.20 \pm 3.21$ \\
\hline Ethyl hexanoate & ND & $98.56 \pm 2.89$ \\
\hline Ethyl octanoate & ND & $153.22 \pm 6.10$ \\
\hline Trans-ethyl decenoate & ND & $6.04 \pm 0.45$ \\
\hline Ethyl decanoate & $11.91 \pm 0.70$ & $0.66 \pm 0.04$ \\
\hline Isopropyl myristate & $27.35 \pm 1.64$ & $6.72 \pm 0.07$ \\
\hline Ethyl dodecanoate & ND & $1.34 \pm 0.08$ \\
\hline Bornyl acetate & $2.64 \pm 0.08$ & $2.51 \pm 0.03$ \\
\hline Isobornyl acetate & $186.14 \pm 6.98$ & $262.36 \pm 7.56$ \\
\hline Total & 320.89 & 794.58 \\
\hline \multicolumn{3}{|l|}{ Alcohols } \\
\hline 1-Pentanol & $2.11 \pm 1.64$ & ND \\
\hline 2-Ethylhexanol & $35.11 \pm 2.46$ & $35.40 \pm 5.26$ \\
\hline 2-Phenylethanol & ND & $1.95 \pm 0.07$ \\
\hline 4-Tert-butylcyclohexanol & $15.66 \pm 1.15$ & $20.61 \pm 1.66$ \\
\hline 2-Tert-butylcyclohexanol & $17.76 \pm 2.10$ & $15.00 \pm 1.23$ \\
\hline 3-Dodecanol & $1.41 \pm 0.06$ & $0.30 \pm 0.02$ \\
\hline 2-Hexadecanol & $9.71 \pm 1.11$ & $8.37 \pm 0.88$ \\
\hline 1-Hexadecanol & $54.83 \pm 2.21$ & $52.51 \pm 3.33$ \\
\hline 2-Methyl hexadecanol & $\mathrm{ND}$ & $1.44 \pm 0.08$ \\
\hline 2-Butyloctanol & $87.28 \pm 4.67$ & $85.63 \pm 3.01$ \\
\hline Total & 169.04 & 221.21 \\
\hline \multicolumn{3}{|l|}{ Terpenoids } \\
\hline Limonene & $3.95 \pm 0.09$ & $0.33 \pm 0.02$ \\
\hline Dihidromircenol & $127.05 \pm 8.10$ & $130.74 \pm 4.88$ \\
\hline Dihidrolinalol & $7.19 \pm 0.92$ & $7.33 \pm 1.45$ \\
\hline Linalool & $12.80 \pm 1.68$ & $12.84 \pm 1.21$ \\
\hline Trans-rose oxide & $6.98 \pm 0.37$ & $3.44 \pm 0.22$ \\
\hline Fenchyl acetate & $2.03 \pm 0.07$ & $2.84 \pm 0.08$ \\
\hline Cis-rose oxide & $1.76 \pm 0.08$ & $0.82 \pm 0.07$ \\
\hline Terpinenol & $0.89 \pm 0.07$ & $0.87 \pm 0.06$ \\
\hline Canfor & $2.28 \pm 0.14$ & $2.44 \pm 1.01$ \\
\hline Neodihydrocarveol & $1.41 \pm 0.06$ & $1.37 \pm 0.05$ \\
\hline Borneol & $2.55 \pm 0.12$ & $2.10 \pm 0.08$ \\
\hline Isoborneol & $3.10 \pm 0.09$ & $2.76 \pm 0.09$ \\
\hline Menthol & $8.53 \pm 1.40$ & $11.10 \pm 2.76$ \\
\hline 1,2-Epoxy limonene & $1.65 \pm 0.09$ & $2.11 \pm 0.10$ \\
\hline$\alpha$-Terpineol & $14.66 \pm 2.61$ & ND \\
\hline$\beta$-Citronellol & $\mathrm{ND}$ & $1.56 \pm 0.06$ \\
\hline Cis-mirtanol & $77.23 \pm 4.72$ & $71.50 \pm 5.24$ \\
\hline Cedrol & $2.44 \pm 0.05$ & $2.30 \pm 0.08$ \\
\hline Total & 276.15 & 256.45 \\
\hline \multicolumn{3}{|l|}{$\mathrm{C}_{13}$ norisoprenoids } \\
\hline (+) $\alpha$-Damascone & $1.21 \pm 0.08$ & $0.66 \pm 0.05$ \\
\hline
\end{tabular}

Table 3 (continued)

\begin{tabular}{lll}
\hline Compounds $\left(\mu \mathrm{g} \mathrm{L}^{-1}\right)$ & Control & O. oeni MS46 \\
\hline$\beta$-Isometilionona & $1.32 \pm 0.15$ & $0.74 \pm 0.04$ \\
$\alpha$-Isometilionona & $10.44 \pm 1.25$ & $8.83 \pm 0.13$ \\
$\beta$-Ionone & $11.04 \pm 2.22$ & $10.54 \pm 1.56$ \\
$\beta$-Methylionone & $4.02 \pm 0.12$ & $4.95 \pm 0.15$ \\
Total & 28.03 & 25.72 \\
Other & & \\
3-Methylbutanal & $9.14 \pm 0.33$ & $0.42 \pm 0.05$ \\
2-Methylbutanal & $5.91 \pm 0.24$ & $0.53 \pm 0.02$ \\
$\alpha$-Hexylcinnamaldehyde & $48.81 \pm 4.22$ & $18.74 \pm 1.78$ \\
2-Butyltetrahydrofuran & $\mathrm{ND}$ & $12.66 \pm 2.01$ \\
Total & 63.86 & 32.35 \\
\hline
\end{tabular}

$N D$ Not detected

Samples of free cell supernatants were obtained by centrifugation before inoculation (control) and at the end of exponential growth phase ( 8 days) of $O$. oeni MS46. Values are the means of three independent experiments \pm standard deviation $(\mathrm{n}=3, p<0.05)$

L-malic acid which was particularly important considering the fastidious nature of these bacteria (Amoroso et al. 1993; Saguir and Manca de Nadra 2002; Saguir et al. 2008), and that cells were not pre-adapted to ethanol presence $(6 \%)$ which is very time-consuming. Bravo-Ferrada et al. (2011) showed that different ethanol concentrations affected growing parameters of isolates of $O$. oeni from Patagonian red wine (Argentinean), but not their malolactic activity. Interestingly, the addition of synthetic glycoside eriocitrin (eriodictyol 7-O- $\beta$-rutinoside) to WBM enhanced bacterial growth, especially $\mu_{\max }$ and L-malic acid utilization rate suggesting that it was metabolized. Thus, monosaccharides (glucose and rhamnose) released from its hydrolysis could enter fermentation pathways for additional energy production (Liu 2002). This result was consistent with a previous observation that $1.0 \mathrm{~g} \mathrm{~L}^{-1}$ glucose was a growth-limiting concentration of $O$. oeni in a synthetic medium (Saguir and Manca de Nadra 1996). On the other hand, the beneficial effect of co-metabolism of L-malate with glucose for growth rate, the biomass formed and to fill amino acids requirements of wine $O$. oeni strains in deficient nutritional condition have been reported (Saguir and Manca de Nadra 2002).

In this present study, $\beta$ Glu, $\alpha$ Ara and $\alpha$ Rha activities were measured in permeabilized cells during growth of the strains tested in WBM and WBME. All of them displayed detectable $\beta$ Glu and $\alpha$ Ara activities regardless medium composition while $\alpha$ Rha activity was only found in WBME. This fact could reflect an adaptive response to their natural habitat possibly with low rhamnose containing-glycosylated compounds concentration. In addition, very low $\alpha$ Rha activities were detected in the strains tested in agreement with previous findings (D'Incecco et al. 2004; 
Grimaldi et al. 2005b). Our results also demonstrated that $\alpha$ Ara activities were near to $\beta$ Glu activities possibly related to a single enzyme acting on $p \mathrm{NP}-\beta \mathrm{Glu}$ and $p \mathrm{NP}-\alpha$ Ara substrates. Recently, a trifunctional enzyme with significant $\beta$-glucosidase, $\beta$-xylosidase and $\alpha$-arabinosidase activities from a rumen metagenomic screening was described in vitro (Gruninger et al. 2014). However, the fact that there was some induction for $\beta$ Glu and $\alpha$ Rha activities in the presence of the synthetic glycoside but not for $\alpha$ Ara activity might be considered as indicative of the involvement of multiple enzymes with limited substrate specificity as previously reported by others investigators (Mansfield et al. 2002; Grimaldi et al. 2000, 2005b; Bloem et al. 2008). On the other hand the slight variability for $\beta$ Glu and $\alpha$ Rha activities among the tested strains highlighted their significance for differentiating and hence selecting strains for its application in the wine glycoside profile modification. However, Gagné et al. (2011) reported that $\alpha$-glucosidase, $\beta$-xylosidase, $\alpha$-arabinosidase and $\alpha$-rhamnosidase activities should be taken much more into consideration when $O$. oeni strains collections are screened. In our study, the fact that the enzymatic activities tested were observed from beginning bacterial growing in WBME indicated that they would contribute toward flavor enhancement during all MLF process in winemaking. This fact could also improve biological activity in wine by increasing the bioavailability of health-promoting metabolites. According to Miyake et al. (1997) the flavonoid glycosides aglycon containing adjacent dihydroxy groups on the B ring like the eriodictyol used in this study showed high antioxidative activity.

From of results obtained we investigated the behavior of the selected MS46 strain in natural glycosides presence. As similar results were obtained for both tested glycosidic extracts, we considerer that treatment applied to must (heating and inoculation) before extraction unlikely impacted on their composition. Therefore, discussion will be centered to spontaneously fermented must glycoside (NFG). Interestingly, when it was included in WBM stimulated bacterial growth, L-malic acid degradation speed as reported by other researchers (D'Incecco et al. 2004; Guilloux-Benatier et al. 1995), and all glycosidase activities tested including $\alpha$ Ara unlike to synthetic glycoside. Moreover, its stimulatory effects were greater than those obtained for the synthetic glycoside, possibly related to its complex nature comprising monosaccharide and various disaccharide-glycosides. However, similar results were recorded for 1 and $5 \mathrm{mg} \mathrm{L}^{-1}$ initial concentrations indicating that another limiting factor beside glucose prevented maximum bacterial growth in culture medium, possibly ethanol that in combination with low $\mathrm{pH}$ disords the $O$. oeni cytoplasmic membrane (da Silveira et al. 2003). Similar increments in residual glucose at the end of MLF were associated to glycoside hydrolysis as reported by Davis et al. (1985). In agreement with our results Ugliano et al. (2003) and D'Incecco et al. (2004) showed activity of $O$. oeni strains on glycosides extracted from Muscat and Chardonnay varieties respectively, while Gagné et al. (2011) reported the most efficient of enzymatic activities of $O$. oeni strains in the presence of untoasted wood extract as natural substrate compared to synthetic substrates. However, our results contrasted with the observations of McMahon et al. (1999) who were unable to demonstrate any hydrolytic activity to Viognier glycosides in a citrate buffer by several commercial $O$. oeni preparations.

It should be noted that the stimulatory effect of NFG on the three glycosidase enzymes activities was consistent with results seen for the synthetic glycoside. However, the greatest activities observed for NFG indicated that natural glycosides must be used to identify more precisely the most promising candidate(s) for application to wine. On the other hand, the improved glycosidase activities of the MS46 strain even in the presence of small glucose concentrations is of great significance taking into account that it is not uncommon for wine to have $1 \mathrm{~g} \mathrm{~L}^{-1}$ glucose. Moreover when previous observations reported that most $\beta$-glucosidase activities of LAB are feedback inhibited by glucose, which could restrict their application (Grimaldi et al. 2000; D'Incecco et al. 2004). In this regards, Yang et al. (2015) described a $\beta$-glucosidase of the glycoside hydrolase 1 family tolerant to or even stimulated by glucose.

To give more light on the aromatic potential of $O$. oeni strains during MLF, the changes in volatile compounds profile were determined in WBM supplemented with NFG $\left(1 \mathrm{mg} \mathrm{L}^{-1}\right)$ at the end of MLF. The presence mainly of acetate esters, terpenoids, and aliphatic alcohols before MLF was consistent with results reported by Maturano et al. (2015) who noted that these secondary metabolite types are produced during AF. Similar result was reported by Lambrechts and Pretorius (2000) for higher alcohols, which can have significant influence on the taste and character of wines when they are found below $300 \mathrm{mg} \mathrm{L}^{-1}$ while terpenes play a fundamental role in giving character to certain cultivars (Palmeri and Spagna 2007).

Examination of the impact of the MS46 strain on volatile compounds profile following MLF showed a large difference in total esters content. Moreover, they markedly increased suggesting the presence of enzyme activities that might synergistically improve wine aroma as esters impart pleasant odors which are reminiscent of fruits (Lambrechts and Pretorius 2000; Lu et al. 2016). Thus, increased acetate and $\mathrm{C}_{6}-\mathrm{C}_{12}$ fatty acids esters including isobornyl acetate confirmed the main role that played $O$. oeni 46 in esters synthesis rather than in their hydrolysis. Ethyl and acetate esters have been shown to be key contributors to the berry fruit characteristics of red wine (Pineau et al. 2009). Similarly to our results, Ugliano and 
Moio (2005) found that $\mathrm{C}_{4}-\mathrm{C}_{8}$ ethyl fatty acid esters and 3-methylbutyl acetate increased with MLF, and their final concentration was dependent on the commercial starter of $O$. oeni employed for the MLF induction. In addition, Izquierdo Cañas et al. (2008) reported that some $O$. oeni strains could synthesize aroma esters under the catalysis of their esterases. However, enzyme activities associated with their biosynthesis had not been well documented for these bacteria, even though they have been shown to exhibit hydrolyzing esterase activities (Davis et al. 1988; Matthews et al. 2006, 2007; Sumby et al. 2009, 2010; Perez-Martin et al. 2013). In this regard, Costello et al. (2013) reported that commercial wine LAB strains possessed two different ester-synthesizing activities with acyl coenzyme A: alcohol acyltransferase activity being greater than reverse esterase, which directly esterifies carboxylic acid and alcohol substrates.

As esters synthesised by $O$. oeni MS46 was significantly greater than esters or alcohols degraded we can conclude that the ester synthesis could be mainly due to precursors liberated from glycoconjugate compounds hydrolysis rather than to carboxylic acids and alcohols present in the medium or derived from esters hydrolysis. For example 2-methylpropyl acetate which was removed by the MS46 strain would supply substrates only accounting for $10 \%$ of the total amount of 3-methylbutyl acetate formed. In addition, no alcohol that decreased its residual concentration after MLF was directly associated with the groups present in the esterified molecules. Hence, the increased glycosidase activities of the MS46 strain against the natural glycoside would indirectly participate in ester synthesis.

Another interesting finding was the formation of new alcohols like 2-phenylethanol and 2-methylhexadecanol alcohols following MLF in agreement with results reported by $\mathrm{Lu}$ et al. (2016). In general, alcohols are formed from the metabolism of amino acids or hexose, via pyruvate (Maicas et al. 1999). However, in the wine-like medium, deficient in sugar and nitrogen sources, their increase could be attributed to the increased glycosidase activities. Schwab et al. (1990) considered that the 2-phenylethanol formation in ciders did not derive from de novo synthesis by the yeast but originated from glycoconjugate precursors hydrolysis present in fruits during AF. In our study, the increased glycosidase activities of $O$. oeni MS46 could also have contributed to the formation of $\beta$-citronellol (citrus note) by liberating substrates for its synthesis (Sarry and Günata 2004). Thus, changes in the volatile profile, mainly esters and in lower extent higher alcohols post-MLF carried out by $O$. oeni MS46 when growing in the wine-like medium supplemented with a natural glycoside, could indirectly be attributed to the glycosidase enzymes production acting in combination with other enzymatic activities such as esterase.
In conclusion, glycosides especially when extracted from grape must positively impacted on growth, malolactic and glycosidase activities of $O$. oeni strains which showed $a$ trend towards greater $\beta$ Glu and $\alpha$ Ara activities than $\alpha$ Rha and tolerance to glucose inhibition. These increments correlated to significant changes in the volatile compounds profile, mainly on formation of aroma esters and in lower extent higher alcohols and others compounds, indicating that esters-synthesizing enzymes, until now little studied in this bacterium, in combination with glycosidic activities would play a relevant role in improving the quality of wines with low ester concentrations. However, further studies on the mechanisms of their formation are currently under development. Thus, results obtained encourage the potential use of selected $O$. oeni strains as MS46 as an effective tool to enhance wine complexity during MLF, mainly for highly fruity, candy and perfume-like aroma incorporation.

Acknowledgements The authors are appreciative of Dr. Viviana Jofré (Laboratorio de Aromas y Sustancias Naturales, Estación Experimental Agropecuaria Mendoza, INTA) and Dr Silvana del Mónaco (Ingeniería de Procesos, Biotecnología y Energías Alternativas, PROBIEN) for technical assistance and comments during the preparation of this manuscript. This work was supported by grants from Consejo Nacional de Investigaciones Científicas y Técnicas (PIP-CONICET) and Consejo de Investigaciones de la Universidad Nacional de Tucumán (PIUNT). Carmen Maturano is postdoctoral fellow and Fabiana María Saguir is investigator in CONICET, Argentina.

\section{Compliance with ethical standards}

Conflict of interest The authors declare that they have no conflict of interest.

\section{References}

Amoroso MJ, Saguir FM, Manca de Nadra MC (1993) Variation of nutritional requirements of Leuconostoc oenos by organic acids. J Int Sci Vigne Vin 27:135-144

Barbagallo R, Spagna G, Palmeri R, Torriani S (2004) Assessment of $\beta$-glucosidase activity in selected wild strains of Oenococcus oeni for malolactic fermentation. Enzyme Microb Technol 34:292-296

Bartowsky EJ, Costello PJ, Henschke PA (2002) Management of malolactic fermentation-wine flavour manipulation. Aust $\mathrm{N} \mathrm{Z}$ Grapegrow Winemak 461:7-12

Bloem A, Lonvaud-Funel A, de Revel G (2008) Hydrolysis of glycosidically bound flavor compounds from oak wood by Oenococcus oeni. Food Microbiol 25:99-104

Boido E, Lloret A, Medina K, Carrai F, Dellacassa E (2002) Effect of $\beta$-glycosidase activity of Oenococcus oeni on the glycosylated flavor precursors of Tannat wine during malolactic fermentation. J Agric Food Chem 50:2344-2349

Bravo-Ferrada BM, Delfederico L, Hollmann A, La Valdés Hens D, Curilén Y, Caballero A, Semorile L (2011) Oenococcus oeni from Patagonian red wines: isolation, characterization and technological properties. Int J Microbiol Res 3:48-55

Campbell-Sills H, Capozzi V, Romano A, Cappellin L, Breniaux M, Lucas P, Biasioli F (2016) Advances in wine analysis by 
PTR-ToF-MS: optimization of the method and discrimination of wines from different geographical origins and fermented with different malolactic starters. Int J Mass Spectrom 397-398:42-51

Costello PJ, Siebert TE, Solomon MR, Bartowsky EJ (2013) Synthesis of fruity ethyl esters by acyl coenzyme A: alcohol acyltransferase and reverse esterase activities in Oenococcus oeni and Lactobacillus plantarum. Appl Microbiol 114:797-806

De Man JC, Rogosa M, Sharpe MR (1960) A medium for the cultivation of lactobacilli. J Appl Bacteriol 23:130-135

D'Incecco N, Bartowsky EJ, Kassara S, Lante A, Spettoli P, Henschke PA (2004) Release of glycosidically bound flavour compounds of Chardonnay by Oenococcus oeni during malolactic fermentation. Food Microbiol 21:257-265

da Silveira MG, Golovina EA, Hoekstra FA, Rombouts FM, Abee T (2003) Membrane fluidity adjustments in ethanol-stressed Oenococcus oeni cells. Appl Environ Microbiol 69:5826-5832

Davis CR, Wibowo D, Eschenbruch R, Lee TH, Fleet GH (1985) Practical implications of malolactic fermentation: a review. Am J Enol Vitic 36:290-301

Davis CR, Wibowo D, Fleet GH, Lee TH (1988) Properties of wine lactic acid bacteria: their potential enological significance. Am J Enol Vitic 39:137-142

Gagné S, Lucas PM, Perello MC, Claisse O, Lonvaud-Funel A, de Revel G (2011) Variety and variability of glycosidase activities in an Oenococcus oeni strain collection tested with synthetic and natural substrates. J Appl Microbiol 110:218-228

Grimaldi A, McLean H, Jiranek V (2000) Identification and partial characterization of glycosidic activities of commercial strains of the lactic acid bacterium, Oenococcus oeni. Am J Enol Vitic $51: 362-369$

Grimaldi A, Bartowsky E, Jiranek V (2005a) Screening of Lactobacillus spp. and Pediococcus spp. for glycosidase activities that are important in oenology. J Appl Microbiol 99:1061-1069

Grimaldi A, Bartowsky E, Jiranek V (2005b) A survey of glycosidase activities of commercial wine strains of Oenococcus oeni. Int $\mathrm{J}$ Food Microbiol 105:233-244

Gruninger RJ, Gong X, Forster RJ, McAllister TA (2014) Biochemical and kinetic characterization of the multifunctional $\beta$-glucosidase $/ \beta$-xylosidase $/ \alpha$-arabinosidase, Bgxa1. Appl Microbiol Biotechnol 98:3003-3012

Guilloux-Benatier M, Guerreau J, Feuillat M (1995) Influence of initial colloid content on yeast macromolecule production and on the metabolism of wine microorganisms. Am J Enol Vitic 46:486-492

Günata ZY, Bitteur S, Brillouet JM, Voirin S, Baumes R, Cordonnier RE (1988) Sequential enzymatic hydrolysis of potentially aromatic glycosides from grapes. Carbohydr Res 184:139-149

Hernandez-Orte P, Cersosimo M, Loscos N, Cacho J, Garcia-Moruno E, Ferreira V (2009) Aroma development from non-floral grape precursors by wine lactic acid bacteria. Food Res Int 42:773-781

Izquierdo PM, García E, Martínez J, Chacón JL (2004) Selection of lactic bacteria to induce malolactic fermentation in red wine of cv. Cencibel. VITIS 43:149-153

Izquierdo Cañas PM, García Romero E, Gómez Alonso S, Palop Herreros ML (2008) Changes in the aromatic composition of Tempranillo wines during spontaneous malolactic fermentation. $\mathrm{J}$ Food Compos Anal 21:724-730

Lambrechts MG, Pretorius IS (2000) Yeast and its importance to wine aroma-a review. S Afr J Enol Vitic 21:97-129

Liu S (2002) A review: malolactic fermentation in wine-beyond deacidification. J Appl Microbiol 92:589-601

Lombardi SJ, Tremonte P, Succi M, Testa B, Pannella G, Tipaldi L, Sorrentino E, Coppola R, Iorizzo M (2012) Effect of phenolic compounds on the growth and L-malic acid metabolism of Oenococcus oeni. J Life Sci 6:1225-1231
Lu Y, Chua J, Huang D, Lee P, Liu S (2016) Biotransformation of chemical constituents of durian wine with simultaneous alcoholic fermentation by Torulaspora delbrueckii. Appl Microbiol Biotechnol 100:8877-8888

Maicas S, Gil JV, Pardo I, Ferrer S (1999) Improvement of volatile composition of wines by controlled addition of malolactic bacteria. Food Res Int 32:491-496

Mansfield AK, Zoecklein BW, Whiton RS (2002) Quantification of glycoside activity in selected strains of Brettanomyces bruxellensis and Oenococcus oeni. Am J Enol Vitic 53:303-307

Massera A, Assof M, Sturm ME, Sari S, Jofré V, Cordero-Otero R, Combina M (2012) Selection of indigenous Saccharomyces cerevisiae strains to ferment red musts at low temperature. Ann Microbiol 62:367-380

Matthews A, Grbin P, Jiranek V (2006) A survey of lactic acid bacteria for enzymes of interest to oenology. Aust J Grape Wine Res $12: 235-244$

Matthews A, Grbin P, Jiranek V (2007) Biochemical characterisation of the esterase activities of wine lactic acid bacteria. Appl Microbiol Biotechnol 77:329-337

Maturano YP, Assof M, Fabani MP, Nally MC, Jofré V, Rodriguez Assaf LA, Toro ME, Castellanos de Figueroa LI, Vazquez F (2015) Enzymatic activities produced by mixed Saccharomyces and non-Saccharomyces cultures: relationship with wine volatile composition. Anton Leeuw Int J G 108:1239-1256

Maturano C, Rivero LV, Rodríguez Vaquero MJ, Saguir FM (2016) The effect of organic acids and sulfur dioxide on $\mathrm{C} 4$ compound production and $\beta$-glucosidase activity of Oenococcus oeni from wines under acidic conditions. Int J Wine Res 8:1-10

McMahon H, Zoecklein BW, Fugelsang K, Jasinsky Y (1999) Quantification of glycosidase activities in selected yeasts and lactic acid bacteria. J Ind Microbiol Biotechnol 23:198-203

Mendoza LM, Manca de Nadra MC, Farías MF (2007) Kinetics and metabolic behavior of a composite culture of Kloeckera apiculata and Saccharomyces cerevisiae wine related strains. Biotechnol Lett 29:1057-1063

Miyake Y, Yamamoto K, Osawa T (1997) Isolation of eriocitrin (eriodictiol 7-rutinoside) from lemon fruit (Citrus lemon BURM. $f$.) and its antioxidative activity. Food Sci Technol Int 3:84-89

Mtshali PS, Divol B, du Toit M (2012) PCR detection of enzymeencoding genes in Leuconostoc mesenteroides strains of wine origin. World J Microbiol Biotechnol 28:1443-1449

Orrillo AG, Ledesma P, Delgado OD, Spagna G, Breccia JD (2007) Cold-active $\alpha$-L-rhamnosidase from psychrotolerant bacteria isolated from a sub-Antarctic ecosystem. Enzyme Microb Technol 40:236-241

Palmeri R, Spagna G (2007) $\beta$-Glucosidase in cellular and acellular form for winemaking application. Enzyme Microb Technol 40:382-389

Pérez-Martín F, Seseña S, Izquierdo PM, Palop ML (2013) Esterase activity of lactic acid bacteria isolated from malolactic fermentation of red wines. Int J Food Microbiol 163:153-158

Pineau B, Barbe JC, Van Leeuwen C, Dubourdieu D (2009) Examples of perceptive interactions involved in specific "red-" and "blackberry" aromas in red wines. J Agric Food Chem 57:3702-3708

Reguant C, Bordons A, Arola L, Rozés N (2000) Influence of phenolic compounds on the physiology of Oenococcus oeni from wine. J Appl Microbiol 88:1065-1071

Saguir FM, Manca de Nadra MC (1996) Organic acids metabolism under different glucose concentrations of Leuconostoc oenos from wine. J Appl Bacteriol 81:393-397

Saguir FM, Manca de Nadra MC (2002) Effect of L-malic and citric acids metabolism on the essential amino acid requirements for Oenococcus oeni growth. J Appl Microbiol 93:295-301

Saguir FM, Loto Campos IE, Manca de Nadra MC (2008) Utilization of amino acids and dipeptides by Lactobacillus plantarum 
from orange in nutritionally stressed conditions. J Appl Microbiol 104:1597-1604

Saguir FM, Loto Campos I, Maturano C, Manca de Nadra MC (2009) Identification of dominant lactic acid bacteria isolated from grape juices. Assessment of its biochemical activities, relevant to flavor development in wine. Int J Wine Res 1:175-185

Sarry JM, Günata Z (2004) Plant and microbial glycoside hydrolases: volatile release from glycosidic aroma precursors. Food Chem 87:509-521

Schwab W, Scheller G, Schreier P (1990) Glycosidically bound aroma components from sour cherry. Phytochemistry 29:607-612

Segurel MA, Baumes RL, Riou C, Razungles AJ (2009) Role of glycosidic aroma precursors on the odorant profiles of Grenache noir and Syrah wines from the Rhone valley. Part 1: sensory study. J Int Sci Vigne Vin 43:199-211

Spano G, Massa S (2006) Environmental stress response in wine lactic acid bacteria: beyond Bacillus subtilis. Crit Rev Microbiol 32:77-86

Sumby KM, Matthews AH, Grbin PR, Jiranek V (2009) Cloning and characterization of an intracellular esterase from the wineassociated lactic acid bacterium Oenococcus oeni. Appl Environ Microbiol 75:6729-6735

Sumby KM, Grbin PR, Jiranek V (2010) Microbial modulation of aromatic esters in wine: current knowledge and future prospects. Food Chem 121:1-16
Tristezza M, di Feo L, Tufariello M, Grieco F, Capozzi V, Spano G, Mita G, Grieco F (2016) Simultaneous inoculation of yeast and lactic acid bacteria: effects on fermentation dynamics and chemical composition of Negroamaro wine. LWT Food Sci Technol 66:406-412.

Ugliano M, Moio L (2005) Changes in the concentration of yeastderived volatile compounds of red wine during malolactic fermentation with four commercial starter cultures of Oenococcus oeni. J Agric Food Chem 53:10134-10139

Ugliano M, Genovese A, Moio L (2003) Hydrolysis of wine aroma precursors during malolactic fermentation with four commercial starter culture of Oenococcus oeni. J Agric Food Chem 51:5073-5078

Voirin SG, Baumes RL, Sapis JC, Bayonove CL (1992) Analytical methods for monoterpene glycosides in grape and wine. Part 2: qualitative and quantitative determination of glycosides in grape. J Chromatogr 595:269-281

Williams P, Cynkar W, Francis I, Gray J, Iland P, Coombe B (1995) Quantification of glycosides in grapes, juices, and wines through a determination of glycosyl glucose. J Agric Food Chem 43:121-128

Yang Y, Zhang X, Yin Q, Fang W, Fang Z, Wang X, Xiao Y (2015) A mechanism of glucose tolerance and stimulation of GH1 $\beta$-glucosidases. Sci Rep 5:17296 